\title{
Series de ficción y documentales latinoamericanos en los catálogos de Netflix y HBO para España
}

\author{
Juan Francisco Gutiérrez Lozano| jfg@uma.es \\ Universidad de Málaga \\ Ashley Jáñez González| ashleyjg@uma.es \\ Universidad de Málaga
}

\author{
Palabras clave \\ "España”; "América Latina”; "Netflix"; "HBO”; \\ "Series"; "Documentales". \\ Sumario \\ 1. Introducción \\ 1.1. Netflix y HBO, ejemplos de la expansión \\ de las nuevas plataformas audiovisuales \\ 1.2. Objetivos \\ 2. Metodología \\ 3. Resultados \\ 3.1. Abundante presencia de series de ficción y \\ documentales latinoamericanos en Netflix \\ 3.2. La oferta de HBO: escasa relevancia de \\ oferta latinoamericana \\ 3.3. Las coproducciones latinoamericanas en \\ Netflix y $\mathrm{HBO}$ \\ 4. Discusión. Nueva difusión para imágenes \\ persistentes \\ 5. Conclusiones \\ 6. Bibliografía
}

\section{Resumen}

Este artículo aborda, mediante una metodología de análisis de contenido, las producciones españolas y latinoamericanas de ficción seriada y documental disponibles en los catálogos de las plataformas de vídeo bajo demanda Netflix y HBO para España. Con el objetivo principal de conocer tanto la cantidad como las características genéricas de estas producciones, el trabajo expone y analiza datos referidos a 2019 sobre los países con mayor representación en estas plataformas, los formatos predominantes en cada una de ellas y los géneros y temáticas más recurrentes. El género del thriller y las temáticas de narcotráfico, crimen y policíaca se imponen entre los contenidos de ficción seriada, mientras que la temática biográfica es la más habitual dentro del género documental. La investigación establece entre sus conclusiones que, en la fecha analizada, Netflix ofrece más contenido de producción latinoamericana que española en su catálogo para España, mientras que en el caso de HBO ocurría lo contrario. Además, el estudio identifica también el peso de los contenidos originales presentes en ambas plataformas, observando cómo ya en esa fecha Netflix apuesta por la producción nacional en aquellos países donde había instalado una sede, caso de España, siendo esta una clara ventana de oportunidad frente a la globalización. HBO tenía aún pendiente esa tarea en su catálogo español en la fecha de la investigación.

Cómo citar este texto:

Juan Francisco Gutiérrez Lozano y Ashley Jáñez González (2021): Series de ficción y documentales latinoamericanos en los catálogos de Netflix y HBO para España, en Miguel Hernández Communication Journal, Vol. 12(2), pp. 355 a 382. Universidad Miguel Hernández, UMH (Elche-Alicante). DOI: 10.21134/mhjournal.v12i.1334 


\title{
Latin American fiction series and documentaries in the Netflix and HBO catalogs for Spain
}

\author{
Juan Francisco Gutiérrez Lozano| jfg@uma.es \\ Universidad de Málaga
}

\author{
Ashley Jáñez González| ashleyjg@uma.es \\ Universidad de Málaga
}

Keywords
"Spain"; "Latin America"; "Netflix"; "HBO";
"Fiction-Series"; "Documentaries".
Summary
1. Introduction
1.1. Netflix and HBO, examples of the expansion
of new audiovisual platforms
1.2. Research aims
2. Methodology
3. Results
3.1. Abundant presence of Latin American fiction
series and documentaries on Netflix
3.2. The HBO offer: little relevance of Latin Amer-
ican offer
3.3. Latin American co-productions on Netflix and
HBO
4. Discussion. New broadcast for persistent images
5. Conclusions
6. Bibliography

recuring theme. This research establishes that Neflix offers more Laphical is the most Spanish productions in its catalog for Spain, while the opposite was the case for HBO España. In addition, the research identifies that Netflix is committed to national production in the countries where it has installed headquarters, like Spain, so it represents an opportunity window in the globalized context. On the other hand, HBO had that task pending in its Spanish catalog on the date of the research.

Juan Francisco Gutiérrez Lozano y Ashley Jáñez González (2021): Series de ficción y documentales latinoamericanos en los catálogos de Netflix y HBO para España, en Miguel Hernández Communication Journal, Vol. 12(2), pp. 355 a 382. Universidad Miguel Hernández, UMH (Elche-Alicante). DOI: 10.21134/mhjournal.v12i.1334 


\section{Introducción}

La irrupción y consolidación de las plataformas de contenidos audiovisuales bajo demanda ha transformado el contexto de producción y distribución televisiva en la última década. Gracias a la presencia en todo el mundo de esta oferta, el desarrollo de nuevos proyectos localizados a escala nacional de plataformas como Netflix, HBO o Amazon Prime Video, entre otras, ha modificado tanto los accesos a las representaciones audiovisuales realizadas desde cada país como su proyección exterior.

Las nuevas ventanas de oportunidad de estos portales globales (Lotz, 2017; Jenner, 2018) han incidido, particularmente, en trastocar algunas dinámicas del contexto televisivo precedente. Así, desde el punto de vista de España y Latinoamérica, por ejemplo, se ha dado un evidente paso hacia un incremento de la visibilidad recíproca de sus producciones, propiciada por la proyección transfronteriza de estas nuevas plataformas. Si la importación de telenovelas copó el acceso principal desde España a producciones latinoamericanas durante muchos años (Medina y Barrón, 2010), las nuevas posibilidades abiertas parecen haber permitido también la eclosión y el conocimiento tanto de nuevos géneros de ficción como de no ficción.

Estas nuevas representaciones audiovisuales, bien realizadas gracias a los nuevos proyectos auspiciados por dichas plataformas, o bien con la difusión más amplia de producciones preexistentes, surten a las audiencias televisivas globales de una mayor diversidad genérica o temática, si bien a veces se repiten prácticas ya consolidadas.

En el caso de México, por ejemplo, Cornelio-Marí subraya que, en las producciones originales realizadas por Netflix desde 2015, y a pesar de la novedad temática o de géneros, la propia plataforma internacional ha acudido a fórmulas conocidas para conseguir la atención de las audiencias:

Cuando llegó el momento de crear nuevo contenido original, Netflix no podía solamente copiar las fórmulas de Televisa y producir nuevas telenovelas que lucieran igual que las tradicionales; en vez de eso, incluyó elementos melodramáticos en comedias, series políticas de acción e incluso programas de concurso (Cornelio-Marí, 2020: 19).

Con independencia de estas inercias, otra de las novedades más significativas de esta situación reside en que, junto a la ficción, las nuevas narrativas documentales, tanto en formato de largometraje como de docuseries de diferente carácter han resultado favorecidas por su expansión en estas plataformas (Binns, 2018). Cuando hablamos de docuseries nos referimos a los contenidos híbridos que mezclan elementos del discurso informativo cercanos al reportaje o documental con mecanismos propios de la ficción (Gordillo, 2009), y que se han convertido en uno de los géneros más transitados y exitosos de las ofertas de estas plataformas globales.

A partir de este contexto, en este artículo pretendemos identificar y analizar la sig- 
nificación reciente de las producciones de ficción y documentales, tanto españolas como latinoamericanas, disponibles en los catálogos de las plataformas de vídeo bajo demanda de Netflix y HBO para España. El objetivo principal es, por un lado, conocer tanto la relevancia numérica como las características genéricas y temáticas de estas producciones, tanto de ficción como de no ficción, en la oferta española de estas dos grandes plataformas. El trabajo realizado ha tenido en cuenta tanto las producciones originales de cada plataforma como aquellas externas que están recogidas en sus ofertas al haberse adquirido los derechos para su emisión.

De paso, y como segundo objetivo, se realizará un acercamiento a cuáles son los países latinoamericanos con mayor representación en el catálogo de ambas plataformas en su oferta española, así como a qué tipo de representaciones (a través de los géneros y temáticas más repetidas en estas producciones) son los más habituales o recurrentes según el país de procedencia. El trabajo también abundará en la presencia y características principales de las coproducciones entre España y Latinoamérica ofrecidas en los catálogos de Netflix y HBO en España, ya que la coproducción internacional ha seguido manteniéndose en los nuevos tiempos de deslocalización de la producción audiovisual impulsados por la instauración de estas plataformas de oferta bajo demanda (VOD).

\subsection{Netflix y HBO, ejemplos de la expansión de las nue- vas plataformas audiovisuales}

En 2017, el porcentaje de penetración en América Latina de los servicios de vídeo bajo demanda era de un $21 \%$ frente al $56 \%$ de la televisión por cable y el $20 \%$ del satélite. Este índice de penetración de las OTT (plataformas over-the-top) era menor ese año que en América del Norte (35\%) o Asia (32\%), pero mayor que en Europa, donde en 2017 se estimaba en un 11\% (Lavín, Gallardo Camacho y Calderón Solé, 2017). Sin embargo, estas cifras han ido mutando en los últimos años, donde se ha producido un incremento exponencial tanto de su penetración como de la oferta disponible. Los efectos de la pandemia y el confinamiento también han generado un fuerte repunte de su consumo (Bustos Díaz, 2020).

La selección de las dos plataformas digitales mencionadas para este estudio se explica al ser las que más tiempo llevan instaladas en España (desde octubre de 2015, Netflix; desde noviembre de 2016 HBO). La penetración de Netflix en el mercado español se estimaba en unos 14 millones de usuarios en 2020 (Lomas, 2020), en torno a un 35\%, si bien datos más recientes calculan que dicha penetración significa cerca del $70 \%$ del mercado de las OTT. Otras plataformas más recientes con tecnología diferente (IPTV, Movistar+, en torno al 20\% de penetración; vid. Gutiérrez Lozano, 2020); o como Amazon Prime (desde diciembre 2016, 13\% de penetración), también han avanzado sus posiciones (García Leiva, 2020). Aunque HBO se mantenía en 2019 en un 11\% de penetración, ha consignado el mayor crecimiento del mercado de las OTT en 2020 con un incremento del 244\% (Cine \& Tele, 2020), aupada por el consumo juvenil. Asi- 
mismo, HBO pese a su más reducido catálogo es la plataforma que obtiene una mejor consideración por parte de los usuarios españoles de estas plataformas en España (ABC, noviembre de 2020).

Netflix se define como el "principal servicio de entretenimiento por internet en el mundo". La empresa norteamericana comenzó su andadura en 1997 como un servicio de alquiler de DVD parecido a un videoclub. En 2007 se produjo su transformación hacia el vídeo bajo demanda en Estados Unidos y, años más tarde, en 2011, este servicio llegó a América Latina y al Caribe. En 2015 empezó a operar en España y entre ese año y 2016 se lanzó a su gran expansión internacional.

La producción deslocalizada o nacionalizada de contenidos originales fue iniciada por Netflix también en 2011, dando un paso relevante a la diversificación de su oferta global. Entonces comenzó tanto a adquirir producciones ajenas para disponer de sus derechos de emisión, como a producir contenidos originales en Europa, Latinoamérica y Asia, dirigidas tanto a los mercados nacionales como globales. Se estima que su audiencia global ronda en la actualidad los 200 millones de espectadores en todo el mundo. Pero pese a esta experiencia de "deslocalización" en busca de nuevos públicos (Straubhaar et al., 2019), el peso de la producción norteamericana y en lengua inglesa sigue predominando en sus catálogos internacionales, como apuntan diferentes estudios realizados (Ordóñez et al., 2018; Penner y Straubhaar, 2020).

HBO, por su parte, tuvo sus inicios como canal de pago por satélite en Estados Unidos en 1972. Desde entonces, el canal y sus formas de suscripción han ido evolucionando hasta la actualidad, donde es sobre todo y también una plataforma de vídeo bajo demanda con capacidad de contratación independiente. HBO España opera como se ha dicho desde 2016 como una división de HBO Europe, y en los próximos meses se espera su transformación y ampliación como HBO Max. En la actualidad, tanto su canal como el servicio de suscripción llegan a más de 60 países, mientras que sus contenidos están disponibles en más de 150 países gracias a su servicio bajo demanda ${ }^{2}$.

Aunque la penetración en el mercado español es menor en $\mathrm{HBO}$ que en el caso de Netflix (cerca de 4 millones de usuarios en 2020; Lomas, 2020), ofrece un catálogo más selectivo y de prestigio. La producción original en España se ha potenciado en los últimos años con los estrenos de series como Patria o 30 monedas, así como con docuseries. HBO España ha mejorado en los últimos tiempos su penetración en España y tras el confinamiento de 2020 se estima que está en un $27,3 \%$, además de ser el servicio mejor valorado por los clientes, como se ha dicho, con un $34,8 \%$ de aprobación (ABC, noviembre de 2020).

\footnotetext{
${ }^{1}$ Centro de prensa de Netflix. Disponible en: https://media.netflix.com/es/about-netflix

${ }^{2}$ Información "Sobre nosotros" en HBO España. Disponible en: https://es.hboespana. com/about
} 
Las plataformas y los nuevos modos de visionado, incluido el llamado binge-watching, o visionado continuado de capítulos (Mikos, 2016) son fenómenos relativamente recientes, por lo que de manera paralela estas dos plataformas OTT han ido recibiendo de forma paulatina una mayor atención académica. La relevancia de Netflix ha sido la más atendida, y en lo que respecta a su producción y desarrollo en el ámbito latinoamericano pueden consultarse, entre otros, los trabajos de Castellano y Meimaridis, 2016; Heredia Ruiz, 2017; Ordóñez et al., 2018 o Straubhhaar et al., 2019. También pueden verse, por ejemplo, los estudios particulares sobre el caso argentino (Lavín et al., 2017), mexicano (Cornelio-Marí, 2020) o brasileño (Días y Navarro, 2018; Meneses y Antonialli, 2019; Penner y Straubhaar, 2020).

\subsection{Objetivos}

El objetivo general de este trabajo es el de conocer la relevancia que tienen en las dos plataformas de vídeo bajo demanda citadas, Netflix y HBO, las producciones latinoamericanas y españolas tanto de series como de documentales. En concreto analizaremos las ofertas que ambas disponen en sus respectivos catálogos para España. Con ello se pretende describir el posible intercambio cultural existente entre España y América Latina a través de la visibilidad, acceso y conocimiento de productos audiovisuales de ficción seriada y de no ficción en estas nuevas plataformas.

Identificar la cantidad y las características genéricas y temáticas del contenido de esta ficción seriada y del documental producido en Latinoamérica y España en estas dos plataformas, en su oferta dirigida al público español, permitirá asimismo detectar qué peso tienen estas producciones dentro de la oferta transnacional de Netflix y HBO. Asimismo, se podrá colegir qué tipo de representación predomina con respecto a las producciones de países latinoamericanos en ellas albergadas y disponibles para España.

Comprobar si la oferta de contenidos producidos en Latinoamérica y España ocupa un lugar destacado dentro del catálogo español de Netflix y HBO, así como qué géneros (ficción o no ficción), qué temáticas dentro de cada uno de ellos o qué tipología de producción (nacionales o coproducciones) ayudará también a dibujar una composición del lugar creado por estas plataformas, la introducción o no de elementos de diversidad, así como la presencia diferenciada de las producciones audiovisuales tanto españolas como latinoamericanas.

\section{Metodología}

Para lograr los objetivos planteados se ha aplicado una metodología de análisis de contenido a la oferta descrita por ambos catálogos de Netflix y HBO en España. Tal y como señala Lobato (2018), estos catálogos cambian de manera constante y varían según los países. Al mismo tiempo, los modos de presentar o identificar los contenidos disponibles hace complicada una búsqueda sistemática (Lopes Fujita y Tolare, 2019). Este hecho es extensible a HBO, por lo que esta circunstancia se ha tenido en cuenta 
en el diseño de la investigación.

Se ha elegido el análisis de contenido cuantitativo de los datos identificadores o descriptivos de las producciones de ambos catálogos como mejor forma de llegar a los objetivos propuestos. Igartua (2006) define el análisis de contenido como un "procedimiento sistemático ideado para examinar el contenido de una información archivada”. El análisis de contenido objetivo, sistemático y cuantitativo resulta fundamental para cualquier investigación científica como el estudio de una parrilla, o como en este caso para el de dos catálogos audiovisuales (Ortega Mohedano y Galhardi, 2012). Lógicamente queda fuera de las pretensiones de esta investigación el acercamiento cualitativo a sus contenidos, que requiere un abordaje distinto al aquí propuesto.

En la primera fase de la investigación, para proceder a la recogida de los datos necesarios, se estableció primero un marco temporal concreto, en este caso la primera quincena del mes de julio de 2019. En dicha quincena se examinaron al completo los catálogos de Netflix y HBO España, mediante un repaso exhaustivo a la oferta de series de ficción, documentales y docuseries. Título a título se identificó de manera general la procedencia del universo completo de ambas ofertas en el marco temporal escogido. La cifra resultante fue la de 2.058 títulos totales en las tres categorías descritas.

A partir de la consulta a ambos catálogos al completo, y mediante la cumplimentación previa de una ficha básica, fueron localizadas las producciones disponibles de los tres géneros descritos tanto de origen latinoamericano como español. La muestra final hallada de producciones de América Latina y España en Netflix y HBO España fue de 154 títulos: 93 series de ficción, 14 docuseries y 47 documentales. Se han considerado todos los títulos cuya producción haya sido bien española, bien latinoamericana, y aquellas coproducciones que bien tenían a un país latinoamericano o a bien a España en su producción.

La segunda fase de la investigación consistió en un análisis descriptivo del contenido detallado sobre cada título, mediante una ficha individualizada para recabar información del mismo y proceder al análisis cuantitativo posterior. Se utilizó la misma ficha para series de ficción y docuseries, debido al carácter seriado de ambos formatos. La ficha utilizada se estableció según lo expuesto en la Tabla 1. 
Tabla 1. Elementos básicos de recogida de información para los títulos analizados

\begin{tabular}{|l|l|}
\hline \multicolumn{2}{|l|}{ Título de la producción } \\
\hline Plataforma \\
\hline País & Fecha de estreno en la plataforma \\
\hline Año de producción & Número de temporadas en la plataforma \\
\hline Cadena de emisión antes de estar \\
\hline Número de capítulos & Media de duración por capítulo \\
& \\
\cline { 2 - 2 } & Minutos totales \\
\hline Creación/Dirección & Productora \\
\hline Coproducción entre países & Idioma original \\
\hline Clasificación por edad & Género \\
\hline Basada en hechos reales & Temática \\
\hline Sinopsis & \\
\hline
\end{tabular}

Fuente: elaboración propia

Para la clasificación genérica, se utilizaron seis grandes géneros a partir de lo señalado por las propias plataformas: drama, comedia, thriller y terror, telenovela, animación y "dramedia". En este último caso la categoría se asignó a las producciones con mezcla de tramas melodramáticas y otras de carácter cómico, que suelen ser categorizadas en las plataformas con ambos descriptores (Herrero Subías y Diego González, 2009).

En cuanto a las temáticas, se aplicó una selección propia de categorías, tomando como referencia tanto la información aportada por las plataformas como aquella referida a los títulos en cuestión que aparecen en catálogos como FilmAffinity e IMdB. Las temáticas a las que se han adscrito las series de ficción y docuseries fueron: Infantil, Juvenil, Familiar, Musical, Ciencia ficción, Política, Época, Romántica, Misterio, Crimen y Policíaca, Narcotráfico, Biográfica, Feminismo y LGTB+, Bélica y Deportiva.

En el caso de los documentales, la ficha utilizada fue similar a la anterior, pero en este caso se eludieron las de "Género" y "Basada en hechos reales", por la lógica asociada al contenido. En cambio, se procedió a completar las categorías temáticas para hacerlas más aplicables al documental, añadiendo algunas más pertinentes: Biográfica, Deporte, Crimen y Policíaca, Musical, Gastronomía, Maternidad, Bélica, Política, Feminismo y LGTB+, Historia, Viajes, Naturaleza y medioambiente, Sociedad, Cine, Terrorismo y Religión.

Piñuel Raigada (2002: 9) define los estudios descriptivos como aquellos que tienen por objeto la "identificación y catalogación de la realidad (...) mediante la definición 
de categorías o clases". De esta manera, este análisis descriptivo exploratorio podrá poner sobre la pista a futuras investigaciones cualitativas que se afanen en otras metodologías complementarias, como puedan ser las de análisis de las propias obras audiovisuales o la de los textos narrativos a ellas asociados, tanto de ficción como de no ficción.

\section{Resultados}

Del total del universo completo de 2.058 títulos, Netflix es la plataforma que ofrece un catálogo más numeroso en España. Dentro de la fecha de análisis escogida, su oferta para España era de 1.150 series —entre las que se contabilizan también las docuseries- y 466 documentales. HBO, por su parte, contaba con 236 series y docuseries y 206 documentales.

En cuanto a la presencia de producciones españolas y latinoamericanas, de los 1.150 títulos del catálogo de Netflix, un 4,52\% eran latinoamericanas, un 2,08\% eran españolas, y un 1,04\% coproducciones que incluían, al menos, a un país latinoamericano o a España. En HBO el porcentaje de sus 236 series y docuseries correspondía a un $5 \%$ de producciones españolas, un $2,54 \%$ de latinoamericanas y un $0,42 \%$ a coproducciones.

Tabla 2. Series y docuseries de producción española y latinoamericana en los catálogos de Netflix y HBO para España (julio 2019)

\begin{tabular}{|c|c|c|}
\hline & Netflix & HBO \\
\hline Series y docuseries en catálogo & 1.150 & 266 \\
\hline De producción española & $24(2,08 \%)$ & $12(5 \%)$ \\
\hline De producción latinoamericana & $52(4,52 \%)$ & $6(2,54 \%)$ \\
\hline Coproducciones & $12(1,04 \%)$ & $1(0,42 \%)$ \\
\hline Total Latinoamérica y España & $88(7,65 \%)$ & $19(7,14 \%)$ \\
\hline
\end{tabular}

Fuente: elaboración propia 
Gráfico 1. Series y docuseries de producción española y latinoamericana en los catálogos de Netflix y HBO para España (julio 2019)
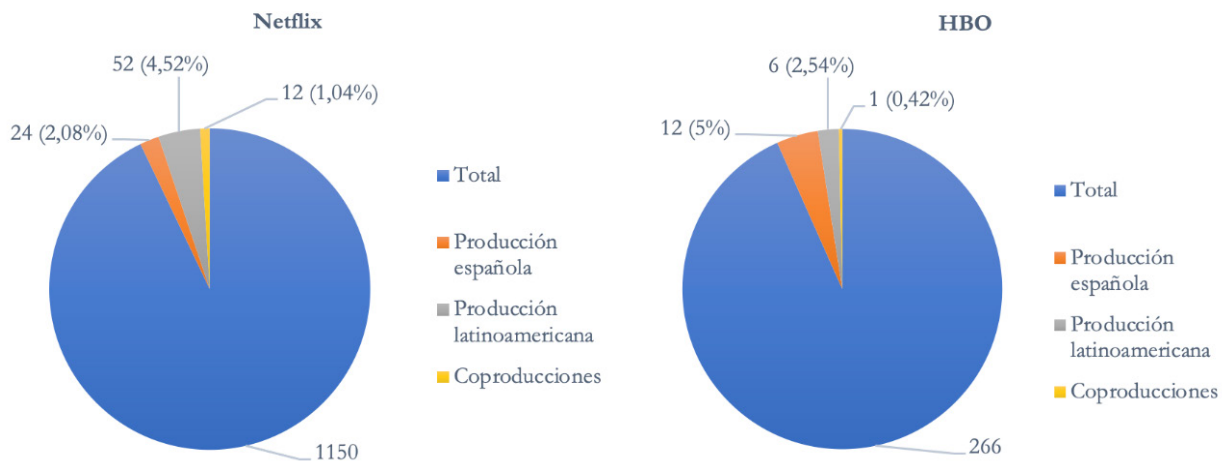

Fuente: elaboración propia

Se comprueba que el porcentaje, aunque con diferente reparto, es similar si agrupamos la procedencia latinoamericana y española de las producciones localizadas en la fecha de estudio, en torno al 7\% tanto en Netflix como en HBO España. En cuanto a las series de televisión, nos encontramos con 93 series de ficción en ambas plataformas. De estas, 76 se encuentran en el catálogo de Netflix y 17 en el de HBO. Respecto a las docuseries, de las 14 docuseries que integran el análisis, 12 son de Netflix y tan solo dos se encuentran en el catálogo de HBO. Cabe destacar que los catálogos de estas plataformas son muy distintos, si bien encontramos un contenido que estaba a la vez tanto en ambos (la serie española $V$ is a vis).

En cuanto al género documental, de los 466 títulos de Netflix, un 5,36\% eran latinoamericanos, un 3,21\% españoles, y un 1,28\% coproducciones. En HBO de los 206 títulos ofrecidos en la categoría de documental, ninguno de ellos es latinoamericano y tan solo uno de ellos correspondía a una producción española. 
Tabla 3. Peso de los documentales de producción española y latinoamericana en los catálogos de Netflix y HBO para España (julio 2019)

\begin{tabular}{|c|c|c|}
\hline & Netflix & HBO \\
\hline Documentales en el catálogo & 466 & 206 \\
\hline Documentales de producción española & $15(3,21 \%)$ & $1(0,48 \%)$ \\
\hline Documentales de producción latinoamericana & $25(5,36 \%)$ & $0(0 \%)$ \\
\hline Coproducciones & $6(1,28 \%)$ & $0(0 \%)$ \\
\hline Total Latinoamérica y España & $46(9,8 \%)$ & $1(0,48 \%)$ \\
\hline
\end{tabular}

Fuente: elaboración propia

Gráfico 2. Documentales de producción española y latinoamericana en los catálogos de Netflix y HBO para España (julio 2019)
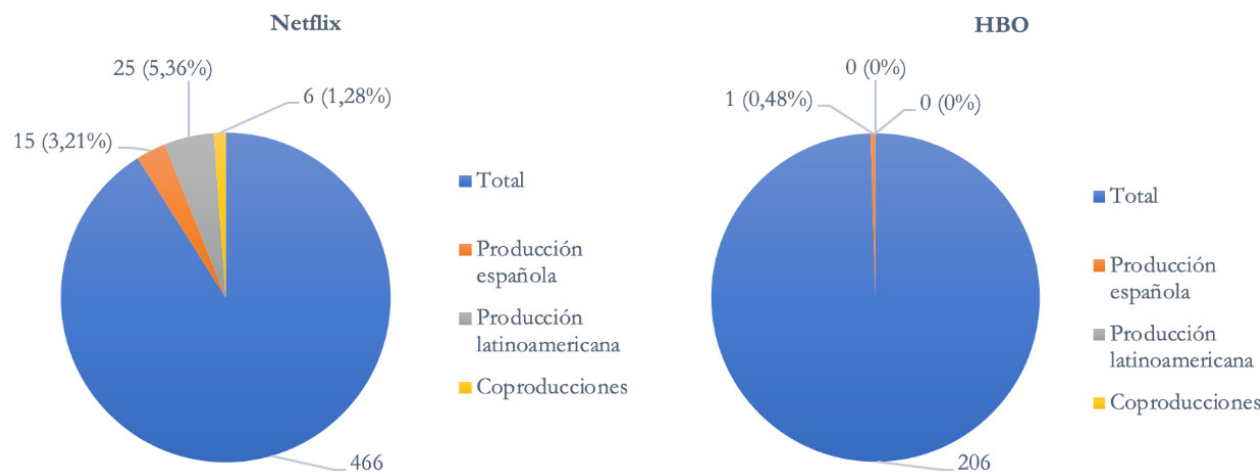

Fuente: elaboración propia

El único documental hallado en $\mathrm{HBO}$ es español, Muerte en León: caso cerrado, especie de spin-off de una de las docuseries que se pueden ver en esta plataforma -Muerte en León- sobre la historia del asesinato de la política española Isabel Carrasco. La diferencia porcentual en cuanto a este género es muy significativa entre la oferta de Netflix y escasez de documentales en HBO.

Del cuadro resumen general (Tabla 4) se trasluce que, de las 154 producciones analizadas, son las series de ficción de procedencia latinoamericana las más abundantes numéricamente, si bien en HBO predominan las españolas. Tras ellas se sitúan las ficciones españolas y después los documentales latinoamericanos, aunque en este caso 
dicho predominio se establece también gracias al amplio catálogo de Netflix.

Tabla 4. Catálogos de Netflix y HBO para España y presencia por procedencia de series de ficción, docuseries y documentales (julio 2019)

\begin{tabular}{|c|c|c|}
\hline & Netflix & HBO \\
\hline Series españolas & $20(14,9 \%)$ & $10(50 \%)$ \\
\hline Series latinoamericanas & $45(33,6 \%)$ & $6(30 \%)$ \\
\hline Series coproducidas & $11(8,2 \%)$ & $1(5 \%)$ \\
\hline Docuseries españolas & $4(3 \%)$ & $2(10 \%)$ \\
\hline Docuseries latinoamericanas & $7(5,2 \%)$ & $0(0 \%)$ \\
\hline Docuseries coproducidas & $1(0,7 \%)$ & $0(0 \%)$ \\
\hline Documentales españoles & $15(11,2 \%)$ & $1(5 \%)$ \\
\hline Documentales latinoamericanos & $25(18,7 \%)$ & $0(0 \%)$ \\
\hline Documentales coproducidos & $6(4,5 \%)$ & $0(0 \%)$ \\
\hline Total & $134(100 \%)$ & $20(100 \%)$ \\
\hline
\end{tabular}

Fuente: elaboración propia

Se constata asimismo cómo el 57,5\% de todos los títulos de Netflix corresponden a series de ficción, docuseries y documentales latinoamericanos no españoles, lo que muestra la visibilidad que ha permitido esta plataforma global. Asimismo, los datos denotan el auge de la ficción original de Netflix España, aunque sean más relevantes en el limitado catálogo latinoamericano ofrecido por HBO.

\subsection{Abundante presencia de series de ficción y documen- tales latinoamericanos en Netflix}

De las 76 series de ficción que ofrece Netflix en el periodo de análisis escogido, 45 son latinoamericanas $(59,2 \%), 20$ españolas $(26,3 \%)$ y 11 son coproducciones $(14,5 \%)$. Por detrás de las series de ficción, en número, se encuentran los documentales. De los hallados en Netflix, 25 de 46 son producciones latinoamericanas (54,3\%), 15 españolas $(32,6 \%)$ y seis $(13 \%)$ coproducciones entre dos o tres países distintos. Por último, se encuentran las docuseries, híbrido entre serie de ficción y documental, de las que se localizan 12, de las cuales $7(58,3 \%)$ son de producción latinoamericana, $4(33,3 \%)$ de producción española y una $(8,3 \%)$ es una coproducción.

Netflix cuenta en su catálogo para España, en este periodo de julio de 2019, con 
20 series de producción española. Algunas son originales de producción propia de la propia plataforma y otras adquiridas. De estos 20 títulos, cinco $(25 \%)$ son series originales de Netflix.

Tabla 5. Series producidas originalmente por Netflix España (2016-2019)

\begin{tabular}{|c|c|c|c|}
\hline Título & $\begin{array}{c}\text { Año de } \\
\text { producción }\end{array}$ & Género & Temática \\
\hline $\begin{array}{c}\text { Paquita Salas (a partir de la } \\
\text { segunda temporada) }\end{array}$ & 2016 & Comedia & Juvenil \\
\hline Las chicas del cable & 2017 & Drama & Época \\
\hline $\begin{array}{c}\text { La casa de papel (a partir de la } \\
\text { tercera temporada) }\end{array}$ & 2017 & Thriller y terror & $\begin{array}{c}\text { Crimen y } \\
\text { policíaca }\end{array}$ \\
\hline Élite & 2018 & Thriller y terror & Juvenil \\
\hline Alta Mar & 2019 & Thriller y terror & $\begin{array}{c}\text { Crimen y } \\
\text { policíaca }\end{array}$ \\
\hline
\end{tabular}

Fuente: elaboración propia

A la hora de contabilizar las series originales de Netflix hay que tener en cuenta que se han incluido como series originales de la plataforma tanto La casa de papel como Paquita Salas, aunque empezaron emitiéndose en otras cadenas y fueron adquiridas por Netflix para su continuación. En el caso de Paquita Salas, la primera temporada fue emitida por Flooxer, la plataforma de contenido online juvenil de Atresmedia, mientras que La casa de papel fue emitida en principio por Antena 3.

La primera serie española de Netflix fue Las chicas del cable, que se estrenó en 2017 tras su paso por Movistar (Cascajosa Virino, 2020), y tras ella vinieron éxitos globales como Élite (2018) y fracasos como Alta Mar (2019). Netflix ha empezado a coproducir series españolas con cadenas generalistas españolas, tanto públicas como privadas (Netflix Newsroom, 2019), y en 2019 inauguró un centro de producción en Madrid como sede para Europa. En cuanto al género de estas producciones de ficción españolas en su catálogo, vemos que hay un claro predominio del thriller, seguido del drama, mientras que entre las temáticas predominan las de crimen y policíacas. 
MHJournal Vol. 12 (2) | Año 2021 - Artículo no 17 (184) - Páginas 355 a 382 - mhjournal.org

Tabla 6. Género de las series de ficción españolas del catálogo de Netflix España (julio 2019)

\begin{tabular}{|c|c|c|}
\hline Género & Series (\%) & Porcentaje \\
\hline Thriller y terror & 8 & $40 \%$ \\
\hline Drama & 7 & $35 \%$ \\
\hline Comedia & 2 & $10 \%$ \\
\hline Animación & 2 & $10 \%$ \\
\hline Dramedia & 1 & $5 \%$ \\
\hline Telenovela & 0 & $0 \%$ \\
\hline Total & 20 & $100 \%$ \\
\hline
\end{tabular}

Fuente: elaboración propia

Tabla 7. Temática de las series de ficción españolas del catálogo de Netflix España (julio 2019)

\begin{tabular}{|c|c|}
\hline Temática & Series (\%) \\
\hline Crimen y policíaca & $7(35 \%)$ \\
\hline Juvenil & $3(15 \%)$ \\
\hline Época & $3(15 \%)$ \\
\hline Infantil & $2(10 \%)$ \\
\hline Ciencia ficción & $2(10 \%)$ \\
\hline Narcotráfico & $2(10 \%)$ \\
\hline Familiar & $1(5 \%)$ \\
\hline Resto de categorías & $0(0 \%)$ \\
\hline Total & $20(100 \%)$ \\
\hline
\end{tabular}

Fuente: elaboración propia

Las series de ficción de producción latinoamericana suponen la categoría más numerosa de las presentes en Netflix en el periodo analizado, si bien solo proceden de cinco países: México (31,1\%), Colombia (26,7\%), Argentina (22,2\%), Brasil $(17,8 \%)$ y Chile $(2,2 \%)$. 
Tabla 8. Series latinoamericanas en Netflix España (julio 2019)

\begin{tabular}{|c|c|}
\hline País & Series $(\%)$ \\
\hline México & $14(31,1 \%)$ \\
\hline Colombia & $12(26,7 \%)$ \\
\hline Argentina & $10(22,2 \%)$ \\
\hline Brasil & $8(17,8 \%)$ \\
\hline Chile & $1(2,2 \%)$ \\
\hline Resto & $0(0 \%)$ \\
\hline Total & $45(100 \%)$ \\
\hline
\end{tabular}

Fuente: elaboración propia

$\mathrm{Al}$ igual que en las series españolas, también predominan en las latinoamericanas el thriller y el drama entre los géneros. Entre las temáticas, predomina el narcotráfico con hasta siete series asociadas, todas de producción mexicana o colombiana. Tres de estas series están basadas en hechos reales: tanto Pablo Escobar, el patrón del mal como Sobreviviendo a Escobar. Alias J. J., ambas colombianas, se acercan a la historia relacionada con la actividad del narcotraficante Pablo Escobar. Además de estas, El desconocido: la historia del Cholo Adrián ofrece una narrativa de ficción basada en la historia del sicario de un narcotraficante mexicano.

Entre otras series basadas en hechos reales, aunque de distinta temática, encontramos la brasileña Túnel de corrupción, serie sobre el escándalo político de las petrolíferas, o Historia de un crimen: Colmenares (Colombia) e Historia de un crimen: Colosio (México), que relatan, con historias ficticias inspiradas en la realidad, dos crímenes cometidos hace años.

Tabla 9. Género de las series de ficción latinoamericanas en el catálogo de Netflix España (julio 2019)

\begin{tabular}{|c|c|}
\hline Género & Series $(\%)$ \\
\hline Thriller y terror & $13(28,9 \%)$ \\
\hline Drama & $12(26,7 \%)$ \\
\hline Comedia & $7(15,5 \%)$ \\
\hline Telenovela & $5(11,1 \%)$ \\
\hline Dramedia & $4(8,9 \%)$ \\
\hline Animación & $4(8,9 \%)$ \\
\hline Total & $45(100 \%)$ \\
\hline
\end{tabular}

Fuente: elaboración propia 
Tabla 10. Temática de las series latinoamericanas en el catálogo de Netflix España (julio 2019)

\begin{tabular}{|c|c|}
\hline Temática & Series $(\%)$ \\
\hline Narcotráfico & $7(15,6 \%)$ \\
\hline Crimen y policíaca & $6(13,4 \%)$ \\
\hline Familiar & $5(11,1 \%)$ \\
\hline Política & $5(11,1 \%)$ \\
\hline Ciencia ficción & $4(8,9 \%)$ \\
\hline Infantil & $3(6,7 \%)$ \\
\hline Juvenil & $3(6,7 \%)$ \\
\hline Biográfica & $3(6,7 \%)$ \\
\hline Época & $2(4,4 \%)$ \\
\hline Romántica & $2(4,4 \%)$ \\
\hline Misterio & $2(4,4 \%)$ \\
\hline Musical & $1(2,2 \%)$ \\
\hline Bélica & $1(2,2 \%)$ \\
\hline Feminismo y LGTB+ & $1(2,2 \%)$ \\
\hline Deportiva & $0(0 \%)$ \\
\hline Total & $45(100 \%)$ \\
\hline
\end{tabular}

Fuente: elaboración propia

En cuanto a la producción propia, Netflix incluye en su catálogo español una gran cantidad de series originales de producción latinoamericana. De las 45 series recogidas en el análisis, 21 de ellas son producciones originales, lo que nos muestra el gran interés de esta plataforma en la producción nacional. El país que más producciones originales tiene es México, ya que Netflix coordina desde este país sus operaciones en Latinoamérica mediante un centro de producción, desde el que en ese mismo año 2019 tenían en marcha hasta 50 películas y series (Tillman, 2019). 
MHJournal Vol. 12 (2) | Año 2021 - Artículo no 17 (184) - Páginas 355 a 382 - mhjournal.org

Tabla 11. Series latinoamericanas originales de Netflix en catálogo para España (julio 2019)

\begin{tabular}{|c|c|c|c|c|}
\hline Título & País & $\begin{array}{c}\text { Año de } \\
\text { producción }\end{array}$ & Género & Temática \\
\hline Club de cuervos & México & 2015 & Dramedia & Familiar \\
\hline $3 \%$ & Brasil & 2016 & Thriller y terror & Ciencia ficción \\
\hline Ingobernable & México & 2017 & Thriller y terror & Política \\
\hline Las leyendas & México & 2017 & Animación & Infantil \\
\hline Samantha! & Brasil & 2018 & Comedia & Juvenil \\
\hline $\begin{array}{c}\text { Club de cuervos presen- } \\
\text { ta: La balada de Hugo } \\
\text { Sánchez. }\end{array}$ & México & 2018 & Dramedia & Familiar \\
\hline $\begin{array}{c}\text { Club de cuervos presen- } \\
\text { ta: Yo, Potro }\end{array}$ & México & 2018 & Comedia & Familiar \\
\hline Diablero & México & 2018 & Thriller y terror & Ciencia ficción \\
\hline$E d h a$ & Argentina & 2018 & Drama & Romántica \\
\hline La casa de las flores & México & 2018 & Comedia & Familiar \\
\hline Túnel de corrupción & Brasil & 2018 & Thriller y terror & Política \\
\hline La ley secreta & Colombia & 2018 & Thriller y terror & Narcotráfico \\
\hline Super drags & Brasil & 2018 & Animación & $\begin{array}{c}\text { Feminismo y } \\
\text { LGTB+ }\end{array}$ \\
\hline Coisa mais linda & Brasil & 2019 & Dramedia & Época \\
\hline $\begin{array}{c}\text { The chosen one (El } \\
\text { escogido) }\end{array}$ & Brasil & 2019 & Thriller y terror & Misterio \\
\hline Go! Vive a tu manera & Argentina & 2019 & Comedia & Juvenil \\
\hline $\begin{array}{c}\text { Historia de un crimen: } \\
\text { Colmenares }\end{array}$ & Colombia & 2019 & Thriller y terror & $\begin{array}{l}\text { Crimen y } \\
\text { policíaca }\end{array}$ \\
\hline $\begin{array}{l}\text { Historia de un crimen: } \\
\text { Colosio }\end{array}$ & México & 2019 & Thriller y terror & $\begin{array}{l}\text { Crimen y } \\
\text { policíaca }\end{array}$ \\
\hline Siempre bruja & Colombia & 2019 & Comedia & Ciencia ficción \\
\hline Tijuana & México & 2019 & Drama & $\begin{array}{l}\text { Crimen y } \\
\text { policíaca }\end{array}$ \\
\hline Yankee & México & 2019 & Thriller y terror & Narcotráfico \\
\hline
\end{tabular}

Fuente: elaboración propia

Los documentales de producción latinoamericana son asimismo muy numerosos en la oferta de Netflix para España. En este caso, de los 46 documentales encontrados, 25 eran latinoamericanos, 15 españoles y 6 coproducciones. Pero, al igual que ocurre en el caso de las series de ficción y las docuseries, son muy pocos los países que tienen 
representación en la oferta. De nuevo Brasil, con nueve, destaca en la lista, si bien en esta ocasión cabe destacar la presencia de Perú con cuatro producciones documentales.

Tabla 12. Documentales latinoamericanos en Netflix España según procedencia (julio 2019)

\begin{tabular}{|c|c|}
\hline País & Series $(\%)$ \\
\hline Brasil & $9(36 \%)$ \\
\hline Argentina & $4(16 \%)$ \\
\hline México & $4(16 \%)$ \\
\hline Perú & $4(16 \%)$ \\
\hline Colombia & $3(12 \%)$ \\
\hline Uruguay & $1(4 \%)$ \\
\hline Otros & $0(0 \%)$ \\
\hline Total & $25(100 \%)$ \\
\hline
\end{tabular}

Fuente: elaboración propia

Entre estas producciones la temática que predomina con diferencia es la biográfica (un $36 \%$ ), y entre todos ellos predominan los que versan sobre personajes del mundo del deporte.

Tabla 13. Temática de documentales latinoamericanos en el catálogo de Netflix España (julio 2019)

\begin{tabular}{|c|c|}
\hline Temática & Series $(\%)$ \\
\hline Biográfica & $6(24 \%)$ \\
\hline Naturaleza y medioambiente & $3(12 \%)$ \\
\hline Maternidad & $3(12 \%)$ \\
\hline Deporte & $2(8 \%)$ \\
\hline Crimen y desapariciones & $2(8 \%)$ \\
\hline Gastronomía & $2(8 \%)$ \\
\hline Política & $2(8 \%)$ \\
\hline Histórica & $2(8 \%)$ \\
\hline Musical & $1(4 \%)$ \\
\hline Cine & $1(4 \%)$ \\
\hline Feminismo y LGTB+ & $1(4 \%)$ \\
\hline Viajes; Sociedad; Bélica; Terrorismo; y Religión & $0(0 \%)$ \\
\hline Total & $25(100 \%)$ \\
\hline
\end{tabular}

Fuente: elaboración propia 
Es destacable asimismo la escasa presencia del documental español en la oferta de Netflix España, pues solo supone el 3,2\% de la oferta completa disponible. Solo se constata en la fecha analizada un documental español de producción propia (Dos Cataluñas) y la tipología de los quince títulos encontrados es muy variada, siendo la más numerosa (3 títulos) la temática bélica.

\subsection{La oferta de HBO: escasa relevancia de oferta latinoa- mericana}

HBO, como se ha indicado, tiene un catálogo mucho más reducido que Netflix y, en concreto, en lo que respecta a las producciones españolas o latinoamericanas encontradas en julio de 2019, era aún más limitado. De los 20 títulos encontrados en su listado, 17 son series de ficción, dos son docuseries y un solo título es de género documental. En esta plataforma solo encontramos representación de producciones latinoamericanas dentro de las series de ficción (6), por lo que es patente el predominio en ella de las series españolas (10 títulos).

En la fecha de la muestra escogida no había aún estrenada ninguna producción original de HBO España, por lo que todas ellas procedían de producciones ajenas, aunque la plataforma ya ha estrenado títulos originales desde entonces, como Patria. Al igual que en Netflix, también es el thriller el género predominante (50\%), seguido del drama $(40 \%)$ y, de manera similar, la temática de crimen y policíaca es la más recurrente (50\%), con series como Bajo Sospecha, La verdad, Pulsaciones o Vis a vis.

Tabla 14. Género de las series de ficción españolas en el catálogo de HBO España (julio 2019)

\begin{tabular}{|c|c|}
\hline Género & Series $(\%)$ \\
\hline Thriller y terror & $5(50 \%)$ \\
\hline Drama & $4(40 \%)$ \\
\hline Comedia & $1(10 \%)$ \\
\hline Dramedia; Telenovela; y Animación & $0(0 \%)$ \\
\hline Total & $10(100 \%)$ \\
\hline
\end{tabular}

Fuente: elaboración propia 


\section{MHJournal Vol. 12 (2) | Año 2021 - Artículo nº 17 (184) - Páginas 355 a 382 - mhjournal.org}

Tabla 15. Temática de las series de ficción españolas en el catálogo de HBO España (julio 2019)

\begin{tabular}{|c|c|}
\hline Temática & Series $(\%)$ \\
\hline Crimen y policíaca & $5(50 \%)$ \\
\hline Época & $3(30 \%)$ \\
\hline Ciencia ficción & $1(10 \%)$ \\
\hline Romántica & $1(10 \%)$ \\
\hline $\begin{array}{c}\text { Política; Infantil; Juvenil; Musical; Familiar; } \\
\text { Misterio; Bélica; Narcotráfico; Biográfica; } \\
\text { Deportiva; y Feminismo y LGTB+ }\end{array}$ & $0(0 \%)$ \\
\hline Total & $10(100 \%)$ \\
\hline
\end{tabular}

Fuente: elaboración propia

En cuanto a las series de producción latinoamericana disponibles en $\mathrm{HBO}$, tres de ellas eran brasileñas $(50 \%)$, dos argentinas $(33,3 \%)$ y una chilena $(16,7 \%)$. Aunque son muchas menos que en el catálogo de Netflix, en este caso, todas estas series eran producciones originales de $\mathrm{HBO}$.

Tabla 16. Series latinoamericanas originales en catálogo de HBO España (julio 2019)

\begin{tabular}{|c|c|c|c|c|}
\hline Título & País & $\begin{array}{c}\text { Año de } \\
\text { producción }\end{array}$ & Género & Temática \\
\hline Epitafios & Argentina & 2004 & Thriller y terror & Crimen y policíaca \\
\hline Prófugos & Chile & 2011 & Drama & Narcotráfico \\
\hline El negocio & Brasil & 2013 & Drama & Romántica \\
\hline Sr. Ávila & Brasil & 2013 & Drama & Crimen y policíaca \\
\hline El jardín de bronce & Argentina & 2017 & Thriller y terror & Crimen y policíaca \\
\hline $\begin{array}{c}\text { La vida secreta de las } \\
\text { parejas }\end{array}$ & Brasil & 2017 & Drama & Crimen y policíaca \\
\hline
\end{tabular}

Fuente: elaboración propia

Es significativa la ausencia de México en el listado, pero en cuanto a los géneros y las temáticas, las series latinoamericanas siguen la tendencia habitual entre las series de ficción encontradas, donde vuelve a predominar la temática de crimen y policíaca $(66,7 \%)$, aunque en este caso sean los dramas $(66,7 \%)$ los que superen a los thrillers $(33,3 \%)$. 
Tabla 17. Género de las series de ficción latinoamericana del catálogo de HBO España (julio 2019)

\begin{tabular}{|c|c|}
\hline Género & Series $(\%)$ \\
\hline Drama & $4(66,7 \%)$ \\
\hline Thriller y terror & $2(33,3 \%)$ \\
\hline Comedia; Dramedia; Telenovela; y Animación & $0(0 \%)$ \\
\hline Total & $6(100 \%)$ \\
\hline
\end{tabular}

Fuente: elaboración propia

Tabla 18. Temática series de ficción latinoamericanas del catálogo de HBO España (julio 2019)

\begin{tabular}{|c|c|}
\hline Temática & Series $(\%)$ \\
\hline Crimen y policíaca & $4(66,7 \%)$ \\
\hline Romántica & $1(16,7 \%)$ \\
\hline Narcotráfico & $1(16,7 \%)$ \\
\hline $\begin{array}{c}\text { Infantil; Juvenil; Musical; Ciencia ficción; Políti- } \\
\text { ca; Época; Familiar; Misterio; Bélica; Biográfica; } \\
\text { Deportiva; y Feminismo y LGTB+ }\end{array}$ & $0(0 \%)$ \\
\hline Total & $6(100 \%)$ \\
\hline
\end{tabular}

Fuente: elaboración propia

A pesar de que hemos visto cómo el acceso al documental es mucho más fácil con la entrada de las plataformas de vídeo bajo demanda, aún en $\mathrm{HBO}$ queda mucho por hacer para acercar su catálogo de documentales al que ofrece Netflix, ya que, si bien HBO cuenta con un buen número de piezas de este género, casi todas son de procedencia estadounidense.

\subsection{Las coproducciones latinoamericanas en Netflix y HBO}

Las coproducciones de diferentes géneros televisivos entre países también están presentes en las nuevas plataformas, aunque según observamos en nuestro análisis, solo Netflix, que contaba en el periodo analizado con 11 coproducciones internacionales latinoamericanas, ofrecía perspectivas positivas en este sentido; HBO, por su parte, solo incluía en su catálogo una coproducción de estas características (con al menos un país latinoamericano o España en la coproducción). En todo caso se detecta como punto negativo, además, que la mayoría de las coproducciones localizadas no surgen de relaciones entre países latinoamericanos y España, sino de estos países con otros no latinoamericanos. Aumentar estas coproducciones podría ser una tendencia de desarrollo futuro en el mercado global audiovisual en español o de ámbito latinoamericano para aprovechar la visibilidad de estas plataformas. 
Tabla 19. Oferta de los catálogos de Netflix y HBO para España según producciones españolas, latinoamericanas y coproducciones (julio 2019)

\begin{tabular}{|c|c|c|}
\hline & Netflix & HBO \\
\hline Producciones españolas & $39(29,1 \%)$ & $13(65 \%)$ \\
\hline $\begin{array}{c}\text { Producciones } \\
\text { latinoamericanas }\end{array}$ & $77(57,5 \%)$ & $6(30 \%)$ \\
\hline Coproducciones & $18(13,4 \%)$ & $1(5 \%)$ \\
\hline Total & $134(100 \%)$ & $20(100 \%)$ \\
\hline
\end{tabular}

Fuente: elaboración propia

La coproducción de ficción mencionada de HBO es Supermax, producida por Mediaset España (España), Central Globo de Produção (Brasil), Televisión Azteca (México), Teledoce (Uruguay) y Televisión Pública Argentina (Argentina). Fue estrenada en las televisiones asociadas a las productoras de cada país y posteriormente añadida al catálogo de HBO.

En el catálogo de Netflix nos encontramos con 17 títulos coproducidos. De ellos hay 6 documentales, una docuserie y 11 coproducciones de series de ficción. De entre estas últimas, seis son coproducciones entre México y Estados Unidos, cinco de ellas producidas por Telemundo en la parte estadounidense. Telemundo es, junto a Univisión, uno de los dos principales proveedores de contenido audiovisual en español en Estados Unidos. Se trata de un canal de televisión digital terrestre de programación generalista especialmente dirigido a audiencias latinoamericanas y que produce también su propio contenido.

Otras coproducciones de ficción encontradas en Netflix son entre Estados Unidos y Colombia, como La reina del Sur, adaptación televisiva de la obra del novelista español Arturo Pérez Reverte. Antena 3 (España) y Telemundo (Estados Unidos) encargaron a la productora colombiana RTI la realización de esta adaptación, pero finalmente se realizaron dos montajes finales independientes para cada país, de modo que la serie española tuvo 13 capítulos, mientras que la coproducción entre Estados Unidos y Colombia se concibió como una telenovela para toda América de 63 capítulos (Palacio y Romero Santos, 2016). Entre el resto de las coproducciones mencionadas de ficción son las establecidas entre España y países no latinoamericanas, como Pocoyó (España y Reino Unido) o Bat pat (España e Italia).

En el caso de la docuserie coproducida por Estados Unidos y México, Cuando conocí al Chapo, se trata de una serie original de Netflix que la plataforma coproduce con otras empresas. Por lo que respecta a los documentales, en Netflix se localizaron en el periodo analizado seis coproducciones, cada una de ellas entre países distintos. A excepción de dos casos, el de una coproducción entre Argentina y Venezuela y otra entre Venezuela y Estados Unidos, el resto son coproducciones transatlánticas que 
incluyen, al menos, un país europeo y uno americano. Nos encontramos en estos casos con coproducciones entre Argentina e Italia, Perú y Reino Unido, España y Estados Unidos y una coproducción entre tres países: España, Colombia y Reino Unido.

\section{Discusión. Nueva difusión para imágenes persistentes}

Del análisis realizado pueden determinarse algunos rasgos significativos de la oferta de Netflix y HBO para España. Eran todavía en la fecha analizada (julio de 2019) escasos los países latinoamericanos con representación en los catálogos de ambas plataformas. Solo Argentina, Brasil, Chile, Colombia y México tienen series de ficción propias en sus listados de esa fecha que han compuesto la base de este estudio. Además de los citados, solo Uruguay está presente en una coproducción de ficción junto a Argentina, Brasil y México. En las docuseries, la representación es todavía menor, ya que solo México, Argentina y Brasil, además de España, incluyen docuseries en la oferta. En el género documental, además de los países mencionados, se suman Perú, Uruguay y Venezuela, aunque este último país solo mediante coproducciones.

Los países que tienen más contenido en las plataformas, además de España, son Argentina, Brasil, Colombia y México, siendo este último país el único representado en todas las categorías: a sus 14 series de ficción se unen tres docuseries y cuatro documentales.

En cuanto a producciones españolas, ya hemos visto que predominan las series de ficción cuyo género es el thriller y cuya temática es el crimen o lo policíaco. Y si nos fijamos en México, el país latinoamericano con más series de ficción en estas plataformas, vemos que los géneros de los que se ofrecen más contenido son el drama y el thriller.

Colombia, por su parte, es el segundo país con más series de ficción es estas plataformas, pero solo cuenta con tres documentales, dos de temática biográfica y otro sobre deporte. En cuanto a las series de ficción, entre las de producción colombiana encontramos que en géneros predominan los dramas y las telenovelas, mientras que la temática más recurrente es, de nuevo, el narcotráfico.

De Argentina, al igual que de España, destacan los thrillers como género y la temática de crimen y policíaca entre las series de ficción. En cuanto a la oferta visible en España en HBO y Netflix procedente de Brasil destaca la de carácter documental, con hasta nueve títulos, entre los que destaca la temática de la maternidad gracias al documental dividido en tres partes $O$ Renascimento do Parto. También en el caso de las producciones brasileñas, como ocurre en las españolas y argentinas, predomina el thriller de crimen o policíaco entre las series de ficción.

\section{Conclusiones}

Netflix y HBO España han ampliado las posibilidades de acceso a producciones audiovisuales latinoamericanas gracias a la amplia oferta de sus servicios de vídeo bajo demanda. El tamaño mayor del catálogo de Netflix y su propia expansión internacional le permite albergar una mayor diversidad cuantitativa latinoamericana tanto en el apartado de las series de ficción como en el género documental, que no se encuentra 
en HBO. En términos porcentuales, en todo caso, las series y docuseries están igualadas en ambos catálogos en torno a un 7\%, mientras que Netflix destaca con un $9 \%$ en documentales frente al insignificante $0,48 \%$ de $\mathrm{HBO}$. De modo que en ningún caso el peso de las producciones españolas y latinoamericanas estos catálogos para España en julio de 2010 alcanzaban el $10 \%$ de su oferta total.

Las producciones españolas y latinoamericanas no ocupan un lugar destacado dentro de estas plataformas en su oferta para España. En el periodo analizado (julio de 2019) el catálogo español de Netflix era el que más contenido latinoamericano y español alojaba: 134 títulos, frente a 20 de HBO. De las producciones halladas en Netflix procedentes del mercado latinoamericano, el 57,5\% era de países diferentes al español, mientras que el 29,1\% procedía de España y el 13,4\% restante eran coproducciones entre dos o más países, si bien las coproducciones recíprocas entre países latinoamericanos resultan muy escasas. En HBO, por el contrario, el porcentaje de contenido de producción española es mayor que el de producción latinoamericana, con un $65 \%$ frente a un $30 \%$, respectivamente. La proyectada transformación de la plataforma en HBO Max en 2021 podría cambiar esta corta representación de producciones de América Latina en su oferta para el público español.

Los países de Latinoamérica presentes en la oferta analizada de ambos catálogos solo han sido ocho (Argentina, Brasil, Chile, Colombia, México, Perú, Uruguay y Venezuela). Frente a esto, la abundante presencia de títulos no latinoamericanos es patente, una carencia que además se agrava por la persistencia temática de algunos géneros recurrentes procedentes de América Latina. El género del thriller y las temáticas relacionadas con lo policíaco, el crimen o el narcotráfico son las prevalentes entre la oferta de ficción procedente de Latinoamérica.

Tanto Netflix como HBO han reforzado su política de producción original deslocalizada en los últimos dos años mediante la potenciación de diversos centros de producción nacionales. Esto podrá aumentar la variedad temática de las producciones en el futuro, así como ofrecer una perspectiva más diferenciada en cuanto al origen de su oferta. De momento la ventana de oportunidad que han abierto no ha sido capaz, todavía, de erradicar algunas inercias de representación ni flujos de producción y difusión previamente existentes.

\section{Bibliografía}

ABC (3 de noviembre de 2020). Amazon Prime Video y HBO, las plataformas que más crecen en España. ABCPlay. Recuperado el 31/01/2021 en https://bit.ly/3gNyvZ5

Binns, D. (2018). The Netflix documentary house style: Streaming TV and slow media. Fusion Journal, 14, pp. 60-71. Recuperado el 23/10/2020 de https://bit.ly/2SVhao2

Bustos Díaz, J. (2020). La penetración de Netflix en el público joven ¿cuestiona el 
modelo televisivo tradicional? Ámbitos. Revista Internacional De Comunicación., (50), pp. 49-61. doi: https://doi.org/10.12795/Ambitos.2020.i50.04

Cascajosa Virino, C. (2020). Bambú Producciones and the transformation of Spanish Television Production. En L. Barra; M. Scaglioni (Eds.) A European Television Fiction Renaissance: Premium Production Models and Transnational Circulation (pp. 227-240). Routledge.

Castellano, M. y Meimaridis, M. (2016). Netflix, discursos de distinção e os novos modelos de produção televisiva. Contemporanea, revista de comunicação e cultura, 14, 02, pp. 193-209. Recuperado el 23/01/2021 en https://bit.ly/35HJEEH

Cine \& Tele (23 de noviembre de 2020). Las plataformas en España, un mercado al borde de la saturación. Recuperado el 23/01/2021 en https://bit.ly/3vUMLnq

Cornelio-Marí, E. M. (2020). Melodrama mexicano en la era de Netflix: algoritmos para la proximidad cultural. Comunicación Y Sociedad, 17, pp. 1-27. doi: https://doi. org/10.32870/cys.v2020.7481

Días, M. y Navarro, R. (2018). Is Netflix dominating Brazil? International Journal of Business and Management Review, Vol. 6, 1, pp. 19-32. Recuperado el 23/01/2021 en https://bit.ly/3quTMdz

García Leiva, M. T. (2020). Plataformas audiovisuales y diversidad: mucho (y muchas) más que Netflix. En: Actas del VII Congreso Internacional de la AE-IC (pp. 679-703). Madrid: Asociación Española de Investigación de la Comunicación.

Gordillo, I. (2009). La hipertelevisión: géneros y formatos. Quito, Ecuador: Quipus, CIESPAL.

Gutiérrez Lozano, J.F. (2020). The Origins of Premium Television Fiction in Spain. Canal+ and Its evolution towards new ways of production and distribution as Movistar+. En L. Barra; M. Scaglioni (Eds.) A European Television Fiction Renaissance: Premium Production Models and Transnational Circulation (pp. 213-226). Routledge.

Heredia Ruiz, V. (2017). Revolución Netflix: desafíos para la industria audiovisual. Chasqui. Revista latinoamericana de Comunicación, 135. doi: https://doi.org/10.16921/ chasqui.v0i135.2776

Herrero Subías, M. y Diego González, P. (2009). Series familiares de televisión: concepto, producción y exportación. El caso de Médico de Familia. Revista Latina de Comunicación Social, $n^{\circ}$. 64, pp. 238-247. Recuperado el 06/11/2020 en https://bit. $\underline{\mathrm{ly} / 35 \mathrm{NAsP} 3}$

Igartua, J. J. (2006). Métodos cuantitativos de investigación en Comunicación. Barcelona, Es- 
paña: Bosch.

Jenner, M. (2018). Netflix and the Re-invention of Television. Springer.

Lavín, E., Gallardo Camacho, J. y Calderón Solé, P. (2017). El consumo del vídeo bajo demanda en Latinoamérica: el caso de Argentina. En J. Herrero; C. Mateos, Del verbo al bit (pp. 178-196). La Laguna, España: Revista Latina de Comunicación social. Recuperado el 1/10/2020 en https://bit.ly/3gM0vMB

Lobato, R. (2018). Rethinking International TV Flows Research in the Age of Netflix. Television \& New Media, 19, 3, pp. 241-256. doi: https://doi. org $/ 10.1177 / 1527476417708245$

Lopes Fujita, M. S. y Tolare, J. B. (2019). O uso do vocabulário controlado no processo de representacão e recuperação de filmes e séries no catálogo da Netflix. VIII Seminário em Ciência da Informação - SECIN. Recuperado el 11/10/2020 en https://bit. $\underline{\mathrm{ly} / 3 \mathrm{wV} 3 \mathrm{ZSY}}$

Lotz, A. (2017). Portals. A Treatise on Internet-Distributed Television. Ann Arbor, MI: Maize Books.

Medina, M. y Barrón, L. (2010). La telenovela en el mundo. Palabra Clave, 13(1), pp. 77-97. Recuperado el 10/01/2021 en https://bit.ly/3vO39pI

Mikos, L. (2016). Digital Media Platforms and the Use of TV Content: Binge Watching and Video-on-Demand in Germany. Media and Communication, 4, 3. doi: https:// doi.org/10.17645/mac.v4i3.542

Netflix Newsroom (2019). Netflix announces five new Spanish original series. Netflix Media Center. Recuperado el 23/10/2020 en https://bit.ly/3d6m6x9

Ordóñez, K., Suing, A., Ramón, M. y Ramírez-Coronel, R. (2018). The Internet and the content audiovisual's. Netflix in Latin America. 13th Iberian Conference on Information Systems and Technologies (CISTI), Caceres, Spain, pp. 1-5. Recuperado el 23/01/2021 en https://bit.ly/3d3gLXv

Ortega Mohedano, F. y Galhardi, C. (2012). Propuesta metodológica para el análisis de contenido de la parrilla de televisión en Brasil: análisis de un caso práctico en el estado de São Paulo. Actas del 20 Congreso Nacional sobre Metodología de la Investigación en Comunicación. Segovia: AEIC. Recuperado el 15/10/2020 en https://bit.ly/3gNQE97

Palacio, M. y Romero Santos, R. (2016). El espacio cultural transnacional en la post-transición. El caso de las series televisivas Amores difíciles y La reina del sur. Secuencias, n. 43-44. doi: http://dx.doi.org/10.15366/secuencias2016.43-44.008 
Penner, T. A. y Straubhaar, J. (2020). Títulos originais e licenciados com exclusividade no catálogo brasileiro da Netflix: um mapeamento dos países produtores. MATRIZes, 14(1), pp. 125-149. doi: https://doi.org/10.11606/issn.1982-8160.v14i1p125-149

Piñuel Raigada, J. L. (2002). Epistemología, metodología y técnicas del análisis de contenido. Estudios de Sociolingüistica. Vol. 3, nº. 1, pp. 1-42. Recuperado el 16/10/2020 en https://bit.ly/3gSngxy

Straubhaar, J. D., Castro, D., Duarte L. G. y Spence, J. (2019). Class, pay TV access and Netflix in Latin America: Transformation within a digital divide. Critical Studies in Television. The International Journal of Television Studies. Vol. 14(2), pp. 233-254. doi: https://doi.org/10.1177/1749602019837793

Tillman, L. (2019). Netflix, drawn to talent, boosts production in Mexico with 50 films and series. Los Angeles Times. Recuperado el 7/11/2020 en https://lat.ms/3gSUBs9

Fuente de financiación: Este trabajo forma parte de los resultados del Proyecto Nacional de I+D "JUVEN-TV: Nuevos consumos frente a viejos estereotipos: Análisis de la recepción por parte de la juventud española de sus representaciones televisivas actuales" (CSO2017-85483-R), financiado por el Ministerio de Ciencia e Innovación del Gobierno de España. 
MHJournal Vol. 12 (2) | Año 2021 - Artículo no 17 (184) - Páginas 355 a 382 - mhjournal.org

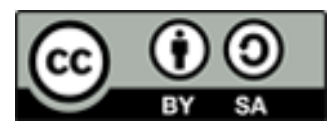

Licencia Creative Commons

Miguel Hernández Communication Journal

mhjournal.org

Juan Francisco Gutiérrez Lozano y Ashley Jáñez González (2021): Series de ficción y documentales latinoamericanos en los catálogos de Netflix y HBO para España, en Miguel Hernández Communication Journal, Vol. 12(2), pp. 355 a 382. Universidad Miguel Hernández, UMH (Elche-Alicante). DOI: 10.21134/mhjournal.v12i.1334 